\section{End-of-life programme for older care home residents: an evaluation study}

James KH Luk ${ }^{1}$, MBBS(HK), MSc (Experimental Medicine)(UBC), FRCP(Edin, Glasg, Irel), FHKCP, FHKAM(Medicine), Wai Kwong Chan², $\mathrm{RN}, \mathrm{BSc}$, MSc, Wing Chun $\mathbf{N g}^{3}$, BSc (NursStud) (Hons), MN, Fei Chan ${ }^{4}$, MBBS(HK),MRCP(UK),FHKCP, FHKAM(Medicine), Tuen Ching Chan ${ }^{1}$, MBBS(HK), MD(HK), MRCP(UK), FHKCP, FHKAM(Medicine), Winnie WY Mok $^{1}$, MBBS(HK),MRCP(UK),FHKCP,FHKAM(Medicine), Felix HW Chan ${ }^{1}$, MBBCh.(Wales), MSc(Wales), FRCP(Ire,Glasg, Edin), FHKCP, FHKAM(Medicine)

\begin{abstract}
Background. The 'enhance community geriatric assessment team service for end-of-life care in residential care homes' (ECEOL) scheme has been implemented in Hong Kong West Cluster since October 2015. The aim of the present study was to examine whether advance care planning (ACP) and do-not-attempt cardiopulmonary resuscitation non-hospitalised (DNACPR-NH) discussion is feasible among residential care home for the elderly (RCHE) residents, whether desired ACP is respected when patients admitted to hospital, and whether there are reductions in emergency attendances, hospital admissions, and health care cost.

Methods. Records of residents of the 26 RCHEs with ECEOL in Hong Kong West Cluster between 1 October 2015 and 31 December 2017 were reviewed. The primary outcome measures were the difference in the numbers of accident and emergency department (AED) attendances, acute and convalescence hospital admissions before and after 6 months of ECEOL, and the compliance with ACP and DNACPR-NH. The secondary outcome measure was reduction in healthcare cost after implementation of ECEOL.
\end{abstract}

Results. A total of 223 residents (60 men and 163 women) were analysed. Of them, 208 (93\%) had DNACPR-NH established and $214(96 \%)$ had ACP established in the RCHE $(n=208)$ or ward $(n=6)$. During the study period, 115 (52\%) residents died. Of them, 69 (60\%) died in designated geriatric convalescence wards. Of the 223 residents, the compliance of DNACPR-NH and ACP was $96 \%$ and $>91.5 \%$, respectively. Comparing 6 months before and after ECEOL, among the 223 residents, the numbers of AED attendances, acute hospital admissions, and convalescence hospital admissions significantly reduced $40 \%, 43 \%$, and $24 \%$, respectively. Comparing alive and death cases, at 6 months after ECEOL, the death cases had significantly more AED attendances, acute hospital admissions, and convalescence hospital admissions. The potential annual cost saving was HK\$6.52 million for 223 residents or HK\$29000 per resident.

Conclusion. ACP and DNACPR-NH discussion was feasible in older $\mathrm{RCHE}$ residents. Compliance to DNACPR-NH and ACP was good, and most residents died in geriatric convalescence wards. ECEOL reduces unnecessary hospital service utilisation and healthcare cost. Further expansion of ECEOL to all RCHEs is recommended.

Key words: Advance care planning; Health care costs; Homes for the aged; Terminal care

\section{ORIGINAL ARTICLE}

\footnotetext{
Department of Medicine and Geriatrics, Fung Yiu King Hospital

2 Community Care Services, Hong Kong West Cluster

3 Department Operation Manager, Community Care Services, Hong Kong West Cluster

4 Department of Medicine, Queen Mary Hospital
}

Correspondence to: Dr James KH Luk, Chief of Service, Department of Medicine and Geriatrics, Fung Yiu King Hospital, 9 Sandy Bay Road, Pokfulam, Hong Kong. Email: lukkh@ha.org.hk 


\section{BACKGROUND}

End-of-life (EOL) issues are common in disease trajectory of older people who have multiple comorbidities. ${ }^{1}$ Those with advanced dementia, organ failure, or degenerative neurological diseases can have unpleasant symptoms similar to those with cancers. ${ }^{2-6}$ Provision of EOL care for this patient group is one aspect of geriatric medicine. ${ }^{7-10}$ In Hong Kong, around $8.5 \%$ of older population are living in residential care home for the elderly (RCHE), ${ }^{11,12}$ and EOL care should be provided to residents with chronic illnesses. ${ }^{1,13-15}$ Indeed, $28.8 \%$ to $35 \%$ of older residents in Hong Kong preferred to die in their RCHEs. ${ }^{16,17}$

Since October 2015, the Hospital Authority of Hong Kong has implemented a territory-wide programme called 'enhance community geriatric assessment team service for end-of-life care in residential care homes' (ECEOL). ${ }^{18,19}$ It aims at providing EOL care for older RCHE residents with terminal conditions. The Gold Standards Framework Prognostic Indicator Guidance ${ }^{20}$ is used to identify suitable candidates based on three triggers: (1) the surprise question of "Would you be surprised if this patient were to die in the next 6 months?", (2) general indicators of decline and deterioration, with increasing need or choice for no further active care, and (3) specific clinical indicators related to certain conditions. Link-nurses act as case managers for targeted RCHE residents.

Among 69 RCHEs in the Hong Kong West Cluster, 26 have joined the ECEOL. The Community Geriatric Assessment Team (CGAT) collaborates with the palliative medical unit of the Grantham Hospital, which provides training to RCHE and CGAT staff, holds regular case conferences with the CGAT, and assists in complex case management. To avoid duplication of service provision, RCHE residents who have been seen by the palliative care team are not recruited into the ECEOL.

In the ECEOL, advance care planning (ACP) is deliberated, and preference of using nasogastric tube feeding, intravenous or subcutaneous hydration, intravenous antibiotics, and non-invasive positive pressure ventilation (NIPPV) at the last stage of life are discussed.The desired ACP choices are recorded in the ACP form, and do-not-attempt cardiopulmonary resuscitation - non-hospitalised (DNACPR-NH) orders are made. Advance directive (AD) is signed if the resident is mentally sound and desires to do so. The RCHE staff bring the ACP, DNACPR-NH records and AD (if available) whenever the residents attend an accident and emergency department (AED) or are admitted to hospital. The healthcare team acts according to the ACP if possible and makes treatment decisions. RCHE residents are regularly visited by link-nurses, and ad hoc problems are managed by link-nurses and geriatricians. If hospital admission is required, designated geriatric convalescence wards with EOL programmes (medical and geriatric wards in Fung Yiu King Hospital or geriatric medical unit in Grantham Hospital) are arranged..$^{10,21,22}$ Residents admitted through AED to acute medical wards in Queen Mary Hospital are taken over by the geriatric team, and step-down care in designated geriatric convalescence wards are arranged.

ACP remains a new concept in Hong Kong. The aim of the present study was to examine whether $\mathrm{ACP}$ and DNACPR-NH discussion is feasible among RCHE residents, whether desired ACP is respected when patients admitted to hospital, and whether there are reductions in emergency attendances, hospital admissions, and health care cost.

\section{METHODS}

This retrospective study was approved by the Institutional Review Board of the University of Hong Kong/Hospital Authority Hong Kong West Cluster (UW 18-224).

Records of residents of the 26 RCHEs with ECEOL in Hong Kong West Cluster between 1 October 2015 and 31 December 2017 were reviewed. Data collected were demographics, religion, source of financial support, functional and mobility status, principal diagnosis, number of other diagnoses, use of enteral feeding, numbers of AED attendance and acute hospital and convalescence hospital admissions 6 months before and after ECEOL, and Abbreviated Mental Test (AMT) score and Barthel Index (20). ${ }^{23,24}$ We also recorded whether residents had established ACP, DNACPR-NH, and/or AD, the place where $\mathrm{ACP}$ discussion took place, the surrogate responsible for ACP discussion, ${ }^{18,25}$ and the content and preferences of the ACP. We also recorded the place and main cause of death for those who died, 
whether residents were cared in the designated geriatric convalescence wards, the length of hospital stay, and compliance with DNACPR-NH, ACP, and AD.

The primary outcome measures were the difference in the numbers of AED attendances, acute and convalescence hospital admissions before and after 6 months of ECEOL, and the compliance with $\mathrm{ACP}$ and DNACPR-NH. The secondary outcome measure was reduction in healthcare cost after implementation of ECEOL.

Statistical analyses were performed using SPSS (Windows version 25; IBM Corp, Armonk [NY], USA). Paired $t$-test and independent $t$-test were used for within-group comparison, and independent $t$-test was used for between-group comparison. All tests were two-tailed, and a $\mathrm{p}$ value of $<0.05$ was considered statistically significant.

TABLE 1

Clinical characteristics of residential care home for the elderly (RCHE)

residents $(n=223)$

\begin{tabular}{|c|c|}
\hline Characteristics & Value $^{*}$ \\
\hline \multicolumn{2}{|l|}{ Types of RCHEs } \\
\hline Care and attention homes or nursing homes & $144(64.6)$ \\
\hline Private RCHEs & $82(27.8)$ \\
\hline Self-finance homes & $17(7.6)$ \\
\hline Age, y & $90.1 \pm 7.6$ \\
\hline No. of men:women & $60: 163$ \\
\hline \multicolumn{2}{|l|}{ Marital status } \\
\hline Widowed & $154(69.1)$ \\
\hline Married & $47(21.1)$ \\
\hline Single & $17(7.6)$ \\
\hline Divorced & $5(2.2)$ \\
\hline \multicolumn{2}{|l|}{ Religion } \\
\hline Christian & $23(10.3)$ \\
\hline Buddha & $20(9)$ \\
\hline Catholics & $16(7.2)$ \\
\hline Traditional Chinese worships & $15(6.7)$ \\
\hline Others & $4(1.8)$ \\
\hline Nil & $145(65)$ \\
\hline On Comprehensive Social Security Assistance & $117(52.5)$ \\
\hline Bedbound or chairbound & $211(94.6)$ \\
\hline Activity of daily living dependent & $201(94.2)$ \\
\hline Barthel Index (20) & $1.7 \pm 2.5$ \\
\hline Abbreviated Mental Test & $1.2 \pm 2.3$ \\
\hline Enteral feeding & $83(37)$ \\
\hline \multicolumn{2}{|l|}{ Principal diagnosis } \\
\hline Advance dementia & $153(68.6)$ \\
\hline Stroke & $30(13.4)$ \\
\hline Organ failure & $26(11.7)$ \\
\hline Neurodegenerative disease other than dementia & $8(3.5)$ \\
\hline Active cancer & $5(2.2)$ \\
\hline No. of other diagnosis & $6.1 \pm 2.2$ \\
\hline
\end{tabular}

* Data are presented as mean \pm standard deviation or No. (\%) of residents 


\section{RESULTS}

A total of 229 RCHE residents recruited into ECEOL during the study period were identified. Six of them were excluded, as they had moved to RCHEs without ECEOL or to RCHEs in other clusters. The remaining 223 residents (60 men and 163 women) were analysed (TABLE 1). Of them, 208 (93\%) had DNACPR-NH established and 214 (96\%) had ACP established in the RCHE $(n=208)$ or ward $(n=6)$ [TABLE 2]. The most common surrogate responsible for ACP discussion was daughters (46\%), followed by sons $(36 \%)$, spouses $(6 \%)$, and adopted children (2\%). Only eight (3.5\%) residents had AD established.

During the study period, 115 (52\%) residents died. The mean duration from recruitment to death was $8.5 \pm 7.4$ months. Of them, $69(60 \%)$ died in designated geriatric convalescence wards, 24 (20.8\%) in acute medical wards, 11 (9.6\%) in AED, 6 (5.2\%) in non-medical wards, and 5 (4.3\%) in non-designated convalescence wards. The length of hospital stay of the index admission was 3.6 \pm 3.3 (range, 1-22) days in acute hospitals and 10.7 \pm 15 (range, 1-75) days in convalescence hospitals. The most common cause of death was chest infection ( $n=70,60.8 \%)$, followed by sepsis other than chest infection $(n=14,12.2 \%)$, heart attack $(n=7,6 \%)$, poor feeding $(n=7,6 \%)$, and cancer $(n=5,4.3 \%)$. Of the 115 residents who died, 107 (93\%) had DNACPR-NH and 106 (92\%) had ACP established. Of the 223 residents, the compliance of DNACPR-NH and ACP was $96 \%$ and $>91.5 \%$, respectively (TABLE 3).

Comparing 6 months before and after ECEOL, among the 223 residents, the numbers of AED attendances, acute hospital admissions, and convalescence hospital admissions significantly reduced $40 \%, 43 \%$, and $24 \%$, respectively (TABLE 4). The reduction in these numbers was also significant in both alive and death cases separately, except for the number of convalescence hospital admissions in death cases. Comparing alive and death cases, at 6 months after ECEOL, the death cases had significantly more AED attendances, acute hospital admissions, and convalescence hospital admissions.

The cost per resident day for medical specialty was $\mathrm{HK} \$ 3842$ in acute hospital and $\mathrm{HK} \$ 2503$ in convalescence hospital. Each AED attendance

TABLE 2

Preferences of those with advance care planning

\begin{tabular}{lc}
\hline Advance care planning & No (\%) of residents $(\mathrm{n}=214)$ \\
\hline Nasogastric tube & $24(11.2)$ \\
Accept & $78(36.4)$ \\
Prefer not & $80(37.4)$ \\
Already on & $32(15)$ \\
Cannot decide at the moment & \\
Parenteral hydration & $148(69.1)$ \\
Agree for intravenous or subcutaneous drip & $11(5.1)$ \\
Prefer subcutaneous over intravenous & $21(9.8)$ \\
Prefer not intravenous or subcutaneous & $34(16)$ \\
Cannot decide at the moment & \\
Intravenous antibiotics & $152(71)$ \\
Accept & $28(13)$ \\
Prefer not & $34(15.9)$ \\
Cannot decide at the moment & \\
Non-invasive positive pressure ventilation & $65(30.4)$ \\
Accept & $114(53.3)$ \\
Do not accept & $35(16.3)$ \\
Cannot decide at the moment &
\end{tabular}


TABLE 3

Compliance with do-not-attempt cardiopulmonary resuscitation (non-hospitalised) and advance care planning in death cases

\begin{tabular}{lc}
\hline & Compliance \\
\hline Do-not-attempt cardiopulmonary resuscitation (non-hospitalised) $[\mathrm{n}=107]$ & $96 \%$ \\
Advance care planning $(\mathrm{n}=106)$ & \\
$\quad$ Nasogastric tube & $95 \%$ \\
Intravenous/subcutaneous drip & $91.5 \%$ \\
Intravenous antibiotics & $95.2 \%$ \\
Non-invasive positive pressure ventilation & $99 \%$ \\
\hline
\end{tabular}

TABLE 4

Numbers of acute and emergency department (AED) attendances, acute hospital admissions, and convalescence hospital admissions in all, alive and death cases 6 months before and after joining the programme

\begin{tabular}{|c|c|c|c|c|}
\hline Parameter & $\begin{array}{l}6 \text { months before } \\
\text { programme* }\end{array}$ & $\begin{array}{l}6 \text { months after } \\
\text { programme }^{\star}\end{array}$ & Reduction & $\mathrm{p}$ Value \\
\hline \multicolumn{5}{|l|}{ All cases $(n=223)$} \\
\hline No. of AED attendance & $2.5 \pm 2.3$ & $1.5 \pm 1.6$ & $40 \%$ & $<0.001$ \\
\hline No. of acute hospital admission & $2.4 \pm 2.3$ & $1.37 \pm 1.4$ & $43 \%$ & $<0.001$ \\
\hline No. of convalescence hospital admission & $0.94 \pm 1.2$ & $0.71 \pm 1.06$ & $24 \%$ & 0.022 \\
\hline \multicolumn{5}{|l|}{ Alive cases $(n=108)$} \\
\hline No. of AED attendance & $2.56 \pm 2.3$ & $1.13 \pm 1.28$ & $56 \%$ & $<0.001$ \\
\hline No. of acute hospital admission & $2.2 \pm 2.3$ & $1.05 \pm 1.14$ & $52 \%$ & $<0.001$ \\
\hline No. of convalescence hospital admission & $0.86 \pm 1.2$ & $0.42 \pm 0.71$ & $51 \%$ & $<0.001$ \\
\hline \multicolumn{5}{|l|}{ Death cases $(n=115)$} \\
\hline No. of AED attendance & $2.67 \pm 2.3$ & $1.85 \pm 1.8^{\dagger}$ & $31 \%$ & $<0.001$ \\
\hline No. of acute hospital admission & $2.56 \pm 2.25$ & $1.7 \pm 1.8^{\ddagger}$ & $33 \%$ & $<0.001$ \\
\hline No. of convalescence hospital admission & $1.0 \pm 1.21$ & $1.0 \pm 1.26^{\S}$ & $0 \%$ & 0.95 \\
\hline
\end{tabular}

Data are presented as mean \pm standard deviation

$\mathrm{p}=0.001$ compared with alive cases

$p=0.003$ compared with alive cases

$\mathrm{p}<0.001$ compared with alive cases

incurred a cost of HK\$1272. In Hong Kong West Cluster, the mean length of hospital stay in acute medical hospital and convalescence hospitals was 2.47 and 11 days, respectively. Comparing 6 months before and after ECEOL, the total cost saving was HK $\$ 2.18$ million [ $(2.4-1.37) \times 223$ residents $\times 2.47$ days $\times$ HK\$3842] for acute hospital admission, $\mathrm{HK} \$ 1.4$ million $[(0.94-0.71) \times 223$ residents $\times$ 11 days $\times$ HK\$2503] for convalescence hospital admission, and HK\$0.28 million [(2.5-1.5) $\times 223$ residents $\times \mathrm{HK} \$ 1272$ ] for AED attendance. The annual expenditure for ECEOL was HK\$1.19 million. The net cost saving in 6 months for 223 residents was $\mathrm{HK} \$ 3.26$ million $[(\mathrm{HK} \$ 2.18$ million $+\mathrm{HK} \$ 1.4$ million + HK\$0.28 million) - HK\$1.19 million / 2]
The potential annual cost saving was HK\$6.52 million $(\mathrm{HK} \$ 3.26$ million $\times 2)$ for 223 residents or HK\$29000 per resident.

\section{DISCUSSION}

$\mathrm{ACP}$ is an integral part of EOL care as it allows patients to decide their future care preferences. ACP covers the patient's state of health and anticipated progression, values and beliefs, treatment expectations and goals, support and nursing care preferences, preferences for life-sustaining treatments, and DNACPR-NH orders. The ACP process involves communications between patients, family members, and healthcare providers. In mentally incapacitated patients, ACP is discussed 
based on the family's knowledge of the patients' values and preferences. A local focus group study elucidated different barriers and facilitators in ACP discussion. ${ }^{26} \mathrm{~A}$ recent study reported that an ACP programme involving residents, family, and different groups of people working in the nursing home was feasible and acceptable by nursing home staff and management. ${ }^{27}$ The present study demonstrated that ACP discussion was feasible in older RCHE residents, with $93 \%$ of them established DNACPR$\mathrm{NH}$ and $96 \%$ established ACP. Nonetheless, some residents or relatives needed more time to consider and discuss among family members and did not establish the ACP and DNACPR-NH at the first geriatrician consultation in EOL clinic. A small number of residents had not established ACP and DNACPR-NH before they died. Discussion of ACP was more suitable in RCHEs where the residents, family members, and RCHE staff were all present to discuss ACP in privacy, with $97 \%$ of ACPs made in RCHEs. $69.1 \%$ of residents/family members preferred the use of intravenous or subcutaneous hydration during the EOL stage; $71 \%$ agreed to use intravenous antibiotics if needed; and 30.4\% accepted NIPPV. When residents were admitted to hospitals, the clinical team would discuss with patients and family members for the risk and benefits of NIPPV. NIPPV could be offered in both acute and convalescence wards if they considered NIPPV as a therapeutic trial.

Compliance with ACP and DNACPR-NH respects the wishes of patients and enhances comfort care. ACP can reduce anxiety, depression, and posttraumatic stress among family members. Two RCHE residents received cardiopulmonary resuscitation despite DNACPR-NH: one died in AED with the RCHE staff having forgot to bring the DNACPR-NH record; the other died in a non-medical ward despite the presence of DNACPR-NH.

At 6 months after ECEOL, AED and hospital service utilisation reduced significantly, particularly acute medical admission, in all, alive, and death cases. As the mean duration from recruitment to death was $8.5 \pm 7.4$ months, the reduction in health service utilisation at 6 months was unlikely to be due to the death of residents within this period. Several factors led to marked reduction in AED attendance and hospitalisation. Ad hoc problems of the residents were managed by link-nurses and geriatricians promptly. This reduces the need of AED attendance and hospital admission and increases residents' confidence to stay in the RCHEs instead of AED. EOL care training was provided to all RCHE staff. This equips the RCHE staff the necessary knowledge and skill to take care of residents with EOL symptoms. During the ACP and DNACPR discussion process, CGAT nurses and geriatricians explained to the residents and their family members the diagnosis, prognosis, and what to expect in future. This increases residents' confidence to manage their EOL symptoms in RCHEs instead of AED. The ECEOL is cost-effective. At 6 months after ECEOL, AED attendances, acute and convalescence hospital admissions were higher in death cases than alive cases. Death cases tended to use more AED and hospital services. Most death cases died in convalescence hospitals, and thus convalescence hospital admission did not reduce significantly. A recent study reported that integration of an ACP model in home healthcare reduced the 60-day hospital readmission rate. ${ }^{28}$

We believe that ECEOL improves the quality of dying by allowing expression of patients wish through ACP and DNACPR-NH. Good compliance with ACP and DNACPR-NH, as well as admission to designated geriatric wards ensure comfort care at the final stage of life. EOL symptoms of residents can be managed in RCHE instead of AED. Successful EOL programme in RCHE requires good medical-social collaboration, adequate staff training and confidence in EOL care, and collaboration with AED and acute and convalescence medical wards.

There were limitations to the present study. In this retrospective study, data accuracy is reliant on the quality of documentation in case notes. Only 6 months of statistics after ECEOL on AED attendances and hospital admissions were analysed; a longer period of analysis is needed to accurately evaluate the AED and hospital service utilisation. The potential cost saving was just a crude calculation, and saving as a result of bed days and AED attendance reduction was only a nominal saving. There was no actual reduction of staff and other expenses as a result of reduced admission. The reasons for nonadherence to ACP were not explored. ACP aims to increase understanding of the patient and guide the healthcare team in providing care and treatment. $\mathrm{ACP}$ is not a legal document and decisions on 
medical treatment are based on the best interests of the patient with reference to ACP. Further research is warranted to understand the reasons for nonadherence and to improve the compliance with ACP.

\section{CONCLUSION}

$\mathrm{ACP}$ and DNACPR-NH discussion was feasible in older RCHE residents. Compliance to DNACPR$\mathrm{NH}$ and $\mathrm{ACP}$ was good, and most residents died in geriatric convalescence wards. ECEOL reduces unnecessary hospital service utilisation and healthcare cost. Further expansion of ECEOL to all RCHEs is recommended.

\section{ACKNOWLEDGEMENTS}

We would like to thank all nurses of the Hong Kong West Community Geriatric Assessment Team for helping to collect data.

\section{FUNDING/SUPPORT}

This research received support from Tung Wah Group of Hospitals Research Fund 2019.

\section{DECLARATION}

The authors have no conflicts of interest to disclose.

\section{REFERENCES}

1. Luk JK, Chan WK, Ng WC, Chiu PK, Ho C, Chan TC, et al. Mortality and health services utilisation among older people with advanced cognitive impairment living in residential care homes. Hong Kong Med J 2013;19:518-24. Crossref

2. Lin OY, Luk JKH, Ng MMT, Chan FHW. Jejunal feeding in an elderly man suffering from advanced Parkinson's disease. Asian J Gerontol Geriatr 2013;8:50-3.

3. Gibbs LM, Addington-Hall J, Gibbs JS. Dying from heart failure: lessons from palliative care. Many patients would benefit from palliative care at the end of their lives. BMJ 1998;317:9612. Crossref

4. Caird FI. The importance of psychological symptoms in Parkinson's disease. Age Ageing 1999;28:335-6. Crossref

5. Mitchell SL, Kiely DK, Hamel MB, Park PS, Morris JN, Fries BE. Estimating prognosis for nursing home residents with advanced dementia. JAMA 2004;291:2734-40. Crossref

6. Marsh GW, Prochoda KP, Pritchett E, Vojir CP. Predicting hospice appropriateness for patients with dementia of the Alzheimer's type. Appl Nurs Res 2000;13:187-96. Crossref

7. World Health Organization Regional Office for Europe. Palliative Care for Older People: Better Practices. Copenhagen; 2011.

8. Luk JK, Liu A, Ng WC, Lui B, Beh P, Chan FH. End-of-life care: towards a more dignified dying process in residential care homes for the elderly. Hong Kong Med J 2010;16:235-6.

9. Luk JKH, Liu A, Ng WC, Beh P, Chan FHW. End-of-life care in Hong Kong. Asian J Gerontol Geriatr 2011;6:103-6.

10. Luk JKH, Chan F, Chan FHW. End-of-life programme for older patients in a geriatric step-down hospital. Asian J Gerontol Geriatr 2018;13:63-7.

11. Census and Statistics Department. Hong Kong Population Projections 2012-2014. Hong Kong Special Administrative Region Government; 2012.

12. LukJKH, Chiu PKC, Chu LW. Factors affecting institutionalization in older Hong Kong Chinese patients after recovery from acute medical illnesses. Arch Gerontol Geriatr 2009;49:e110-4. Crossref

13. Luk JKH, Pau MML, Chan FHW, Yu C. Outreach geriatric private nursing home service in Hong Kong Central and Western cluster. J Hong Kong Geriatr Soc 2002;11:5-10.

14. Lo RSK, Woo J. Palliative care in the elderly. J Hong Kong Geriatr Soc 2000;10:16-24.

15. Ho AH, Luk JK, Chan FH, Chun Ng W, Kwok CK, Yuen JH, et al. Dignified palliative long-term care: an interpretive systemic framework of end-of-life integrated care pathway for terminally ill Chinese older adults. Am J Hosp Palliat Care 2016;33:43947. Crossref

16. Luk JKH, Chu LW, Chan FHW, et al. A study of the knowledge and preferences in Chinese elderly concerning advance directive. Hospital Authority Convention; 2007.

17. Chu LW, Luk JK, Hui E, Chiu PK, Chan CS, Kwan F, et al. Advance directive and end-of-life care preferences among Chinese nursing home residents in Hong Kong. J Am Med Dir Assoc 2011;12:143-52. Crossref

18. Luk JKH, Chan FHW. End-of-life care for advanced dementia residents in residential care home: a Hong Kong perspective. Ann Palliat Med 2018;7:359-64. Crossref

19. Luk JK. End-of-life services for older people in residential care homes in Hong Kong. Hong Kong Med J 2018;24:63-7. Crossref

20. The GSF Prognostic Indicator Guidance. Available at http:// www.goldstandardsframework.org.uk/cd-content/uploads/files/ General\%20Files/Prognostic\%20Indicator\%20Guidance\%20 October\%202011.pdf. Accessed on 28 March 2019.

21. Luk JK, Chan FH, Hui E, Tse CY. The feeding paradox in advanced dementia: a local perspective. Hong Kong Med J 2017;23:30610. Crossref

22. Luk JKH, Chan TC, Mok WWY, Wong EKC, Chan FHW. Endof-life clinical plan in a geriatric step-down hospital. Asian J Gerontol Geriatr 2016;11:42-7.

23. Chu LW, Pei CKW, Ho MH, Chan PT.Validation of the Abbreviated Mental Test (Hong Kong version) in the elderly medical patient. Hong Kong Med J 1995;1:207-11.

24. Mahoney FI, Barthel DW. Functional evaluation: the Barthel Index. Md State Med J 1965;14:61-5. Crossref

25. Guardianship Board. Available at: http://www.adultguardianship. org.hk. Accessed on 28 March 2019.

26. Lau BHP, Luk JKH, Fong CHC, Chow AYM, Chan CLW, Ng $\mathrm{WC}$, et al. Facilitators and barriers to advance care planning programmes targeting older care home residents: a qualitative study. Asian J Gerontol Geriatr 2019;14:81-8. Crossref

27. Gilissen J, Pivodic L, Wendrich-van Dael A, Gastmans C, Vander Stichele R, Van Humbeeck L, et al. Implementing advance care planning in routine nursing home care: the development of the theory-based ACP+ program. PLoS One 2019;14:e0223586. Crossref

28. Mauleon J, Staffileno BA. Integration of an advance care planning model in home health: favorable outcomes in end-oflife discussions, POLST rates, and 60-day hospital readmissions. Home Healthc Now 2019;37:337-44. Crossref 